\title{
Plantas tóxicas para ruminantes e equídeos da microrregião do Cariri Cearense
}

\author{
Plant poisonings in ruminants and horses in Southern Ceará, Northeastern Brazil
}

\author{
Cícero Wanderlô Casimiro Bezerra ${ }^{\mathrm{I}}$ Rosane Maria Trindade de Medeiros $^{{ }^{*}}$ \\ Beatriz Riet Correa Rivero ${ }^{\mathrm{I}}$ Antônio Flávio Medeiros Dantas ${ }^{\mathrm{I}}$ Franklin Riet Correa Amaral $^{\mathrm{I}}$
}

\section{RESUMO}

Em um levantamento, feito no período de agosto de 2009 a novembro de 2010, sobre as plantas tóxicas para ruminantes e equídeos no Cariri Cearense (municípios de Juazeiro do Norte, Crato, Barbalha e Missão Velha), foram realizadas 21 entrevistas a produtores, médicos veterinários, engenheiros agrônomos e técnicos agropecuários. As intoxicações por Ipomoea asarifolia, mencionada por $38 \%$ e $19 \%$ dos entrevistados como tóxicas para bovinos e ovinos, respectivamente, e Enterolobium contotisiliquum, mencionada como tóxica para bovinos (47,6\% dos entrevistados) e ovinos $(4,7 \%)$ foram as mais frequentemente mencionadas. Ocorrem, também, na região, intoxicações por Mascagnia rigida (mencionada por 38\% do entrevistados), Anadenanthera colubrina var. cebil (=A. macrocarpa) (14\%), Ricinus communis (14\%), Thiloa glaucocarpa (9\%) e Sorghum halepense (4\%) em bovinos, Brachiaria decumbens em ovinos e bovinos (38\%), Mimosa tenuiflora em ovinos, caprinos e bovinos (38\%), Manihot spp. em bovinos e caprinos (28\%) e Leucaena leucocephala em ovinos e equinos (4\%). Seis plantas não conhecidas anteriormente como tóxicas, mas mencionadas como causa de intoxicação pelos entrevistados, foram testadas experimentalmente em diferentes doses. Somente Casearia commersoniana resultou tóxica para caprinos na dose diária de $20 \mathrm{~g} \mathrm{~kg}^{-1}$ de peso vivo por 2-4 dias. Os sinais clínicos, semelhantes aos descritos pelos produtores, foram de relutância em movimentar-se, meteorismo discreto, polaquiúria, vocalização, ingurgitamento da jugular e pulso jugular, andar cambaleante, quedas, espasticidade dos membros, movimentos de pedalagem, opistótono, taquicardia e taquipneia, seguidos de bradicardia e bradipnéia. A morte ocorreu 6 e 19 horas após o início dos sinais. Não foram encontradas lesões macroscópicas nem histológicas de significação. Conclui-se que as intoxicações por plantas são uma causa importante de perdas econômicas para a região, cuja população é de 53.473 bovinos, 4.799 caprinos, 9.149 ovinos e 7.060 equídeos.
Palavras-chave: plantas tóxicas, intoxicação por plantas, semiárido, Casearia commersoniana.

\section{ABSTRACT}

A survey on toxic plants for ruminants and equidae was performed on the municipalities of Juazeiro do Norte, Crato, Barbalha, and Missão Velha on the Ceará state, Northeastern Brazil. Twenty one interviews were realized with farmers, veterinary practitioners, agronomists and agriculture technicians. Poisonings by Ipomoea asarifolia mentioned in 38\% and 19\% interviews as toxic for bovines and sheep, respectively, and Enterolobium contotisiliquum, mentioned as toxic for cattle (47.6\% of the interviews) and sheep (4.7\%), were more frequent. Also occur in the region poisonings by Mascagnia rigida (38\% of the interviews), Anadenanthera colubrina var. cebil (=A. macrocarpa) (14\%), Ricinus communis (14\%), Thiloa glaucocarpa (9\%), and Sorghum halepense (4\%) in cattle, Mimosa tenuiflora in cattle, sheep, and goats (38\%), Brachiaria decumbens in sheep and cattle (38\%), Manihot spp. in cattle and goats (28\%), and Leucaena leucocephala in sheep and horses (4\%). Several plants previously unknown as toxic, but mentioned by the respondents as poisonous, were given to experimental animals at different doses. Only Casearia commersoniana was toxic to goats at the daily doses of $20 \mathrm{~g} \mathrm{~kg}$ ${ }^{1}$ body weight during 2-4 days. Clinical signs, similar to those reported by the farmers, were stiffness, mild bloat, polaquiuria, vocalization, jugular engorgement and pulsation, swaying gait, falling, spasticity, paddling movements, opisthotonos, and tachyicardia and dyspnea followed by bradycardia and bradypnea. Deaths occurred 6 and 19 hours after first clinical signs. No significant gross or histologic lesions were observed. It is concluded that poisonings by plants are important cause of losses in the region, which has a population of 53,473 bovines, 4,799 goats, 9,149 sheep, and 7,060 equidae.

Key words: poisonous plants, plant poisoning, semiarid, Casearia commersoniana.

ICentro de Saúde e Tecnologia Rural (CSTR), Hospital Veterinário (HV), Universidade Federal de Campina Grande (UFCG), 58700-000, Patos, PB, Brasil. E-mail: rmtmed@uol.com.br. *Autor para correspondência. 


\section{INTRODUÇÃO}

No Brasil, as perdas anuais por mortes causadas por plantas tóxicas são estimadas em aproximadamente um milhão de bovinos por ano (RIETCORREA \& MEDEIROS, 2001). Muitas dessas intoxicações por plantas foram diagnosticadas na região Nordeste e algumas mediante levantamentos sistemáticos em diferentes regiões dos estados do Rio Grande do Norte (SILVA et al., 2006), Piauí (MELLO et al., 2010) e Paraíba (ASSIS et al., 2009, 2010). No entanto, no Ceará, há poucos relatos diagnosticando intoxicações por plantas. Este trabalho teve como objetivo determinar as intoxicações por plantas que ocorrem em ruminantes e equídeos no Cariri Cearense.

\section{MATERIAL E MÉTODOS}

O trabalho foi realizado de agosto de 2009 a novembro de 2010 em quatro municípios (Juazeiro do Norte, Crato, Barbalha e Missão Velha) da microrregião do Cariri. A região, localizada no Vale do Cariri, mesorregião sul do Estado do Ceará, tem 460.964 habitantes e uma área de $2.655 .982 \mathrm{~km}^{2}$. A vegetação é caracterizada por dois elementos geográficos, a caatinga, típica do semiárido brasileiro, e a Chapada do Araripe, onde predomina uma vegetação subperenifólica de matas úmidas, com transição no sentido norte-sul para o cerradão, cerrado e carrasco. A microrregião do Cariri Cearense apresenta um clima semiárido quente, com apenas um regime de chuvas, concentrado nos meses de fevereiro a maio com pluviosidade média entre 800 e $1100 \mathrm{~mm}^{-1}$ ano ${ }^{-1}$ A região tem uma população de 53.473 bovinos, 4.799 caprinos, 9.149 ovinos e 7.060 equídeos (IBGE 2011). A maioria das propriedades rurais é de agricultores familiares e pequenos agricultores com criação extensiva em pastagens nativas.

Para esta pesquisa, foram visitadas, no mínimo, três propriedades por município. Foram entrevistadas 21 pessoas, sendo quatro médicos veterinários, dois agrônomos, dois técnicos agrícolas que residiam ou prestavam assistência técnica na região e treze produtores residentes nos municípios visitados. A entrevista foi baseada no preenchimento de três formulários semelhantes aos utilizados por SILVA et al. (2006). No formulário 1, constavam os nomes científico e popular das plantas, assim como perguntas sobre existência da planta na região, cujos casos de intoxicação o entrevistado houvesse presenciado. No momento das entrevistas, fotos das plantas eram apresentadas ao entrevistado. No formulário 2, eram anotados nome e os sinais clínicos causados por plantas suspeitas de toxicidade. No formulário 3, eram anotados dados epidemiológicos sobre a suspeita da intoxicação descrita pelo entrevistado.

No formulário 1, foram incluídas as 33 plantas seguintes: Aspidosperma pyrifolium, Brachiaria spp., Crotalaria retusa, Enterolobium contortisiliquum, Indigofera suffruticosa, Ipomoea asarifolia, Ipomoea carnea, Ipomoea riedelli, Lantana camara, Manihot spp., Mascagnia rigida, Neriun oleander, Piptadenia macrocarpa, Plumbago scandens, Prosopis juliflora, Ricinus communis, Sorghun vulgare, Sorghun halepense, Stryphnodendron coriaceum, Thiloa glaucocarpa, Mimosa tenuiflora, Marsdenia megalantha, Centratherum brachylepis, Palicourea spp., Tephrosia cinerea, Amaranthus spp, Froelichia humboldtiana, Turbina cordata, Ipomoea sericophylla, Solanum paniculatum, Cnidoscolus phyllacanthus, Senna occidentalis e Leucaena leucocephala.

Algumas plantas que foram citadas como tóxicas pelos entrevistados, que não estavam contidas no formulário 1 , foram coletadas para realização experimental de sua toxicidade em caprinos ou ovinos e enviadas à Botânica Prof ${ }^{a}$. Dra. Maria Arlene Pessoa da Silva do Herbário Caririense Dárdano Andrade de Lima, pertencente à Universidade Estadual do Cariri (URCA) para identificação. Casearia commersoniana foi enviada ao Jardim Botânico do Rio de Janeiro e identificada pelo Dr. Ronaldo Marquete. Para realização de estudo experimental da toxicidade, as plantas foram coletadas na propriedade onde ocorreram os surtos e mantidas sob refrigeração até o momento de administração aos animais. Um experimento com $\boldsymbol{C}$. commersoniana em caprino foi realizado na propriedade onde ocorreu o surto.

Os caprinos e ovinos foram pesados e colocados em baias individuais. Após jejum de 24 horas, a planta era fornecida para consumo espontâneo. Se os animais não ingeriam espontaneamente a planta, ela era administrada nas doses de 10 a $20 \mathrm{~g} \mathrm{~kg}^{-1}$ peso corporal, colocando-se pequenas quantidades na boca do animal, esperando que ele mastigasse e deglutisse. Posteriormente à administração, era oferecido concentrado em quantidade equivalente a $1 \%$ do peso vivo, além de feno de Cynodon spp. (capim tifton) e água ad libitum.

\section{RESULTADOS}

O trabalho apontou 11 plantas de toxicidade comprovada e com sinais clínicos semelhantes aos descritos previamente na literatura e seis plantas citadas como tóxicas na região, mas sem comprovação científica. 
Plantas de toxicidade comprovada

Ipomoea asarifolia foi relatada por 11 (52\%) dos entrevistados que afirmam ter visto intoxicações por esta planta em bovinos (38\%) ou ovinos (19\%). Um técnico agrícola relatou que animais intoxicados por esta planta (principalmente ovinos jovens) caíam por falta de equilíbrio e morriam afogados em locais com água (bebedouros, poços, buracos, açudes). Afirmou, também, ter conhecimento de aproximadamente 20 surtos de intoxicação por salsa por ano. Um médico veterinário relatou que diagnostica aproximadamente cinco surtos de intoxicação por salsa por ano. Em uma propriedade em que há grande quantidade da planta e pouco alimento, ocorreu um surto, entre setembro e outubro de 2007, em um rebanho de aproximadamente 150 caprinos e ovinos. Destes, 30 (20\%) adoeceram, 20 (13,3\%) se recuperaram e $10(6,66 \%)$ morreram apresentando tremores, andar cambaleante, anorexia, decúbito e morte.

Enterolobium contortisiliquum foi relatada como tóxica por 10 (47\%) dos entrevistados que observaram intoxicação por vagens desta árvore, causando fotossenssibilização ou aborto em bovinos e fotossenssibilização em ovinos. Um produtor relatou ocorrer aproximadamente seis abortos por ano em bovinos em uma propriedade no município de Crato. Dois produtores relataram ter observado quatro casos, cada um, de abortos em bovinos. Um médico veterinário relatou ocorrer cinco casos de intoxicação por ano em bovinos. Durante a visita a uma fazenda, observou-se um ovino macho da raça Santa Inês intoxicado por vagens de $\boldsymbol{E}$. contortisiliquum. O animal tinha áreas despigmentadas na cabeça e tronco e apresentou febre, edema de cabeça, orelhas e barbela e dermatite da orelha e lábio superior, obstrução parcial por edema das narinas com dificuldade respiratória, lacrimejamento bilateral (Figura 1 Ae B) e congestão da mucosa ocular. Deitava e levantava frequentemente em sinal de inquietude, apresentava vocalização frequente e fugia da luz solar direta. Morreu após um curso clínico de três dias e à necropsia foi observado presença de sementes da planta no conteúdo rumenal e áreas hemorrágicas no tecido subcutâneo da região dorsal. O fígado estava amarelado e com aumento do padrão lobular (Figura 1C). Na histopatologia, foi observada degeneração vacuolar no citoplasma de hepatócitos nas porções centro-lobular a médio-zonal. Alguns hepatócitos apresentavam vacúolos

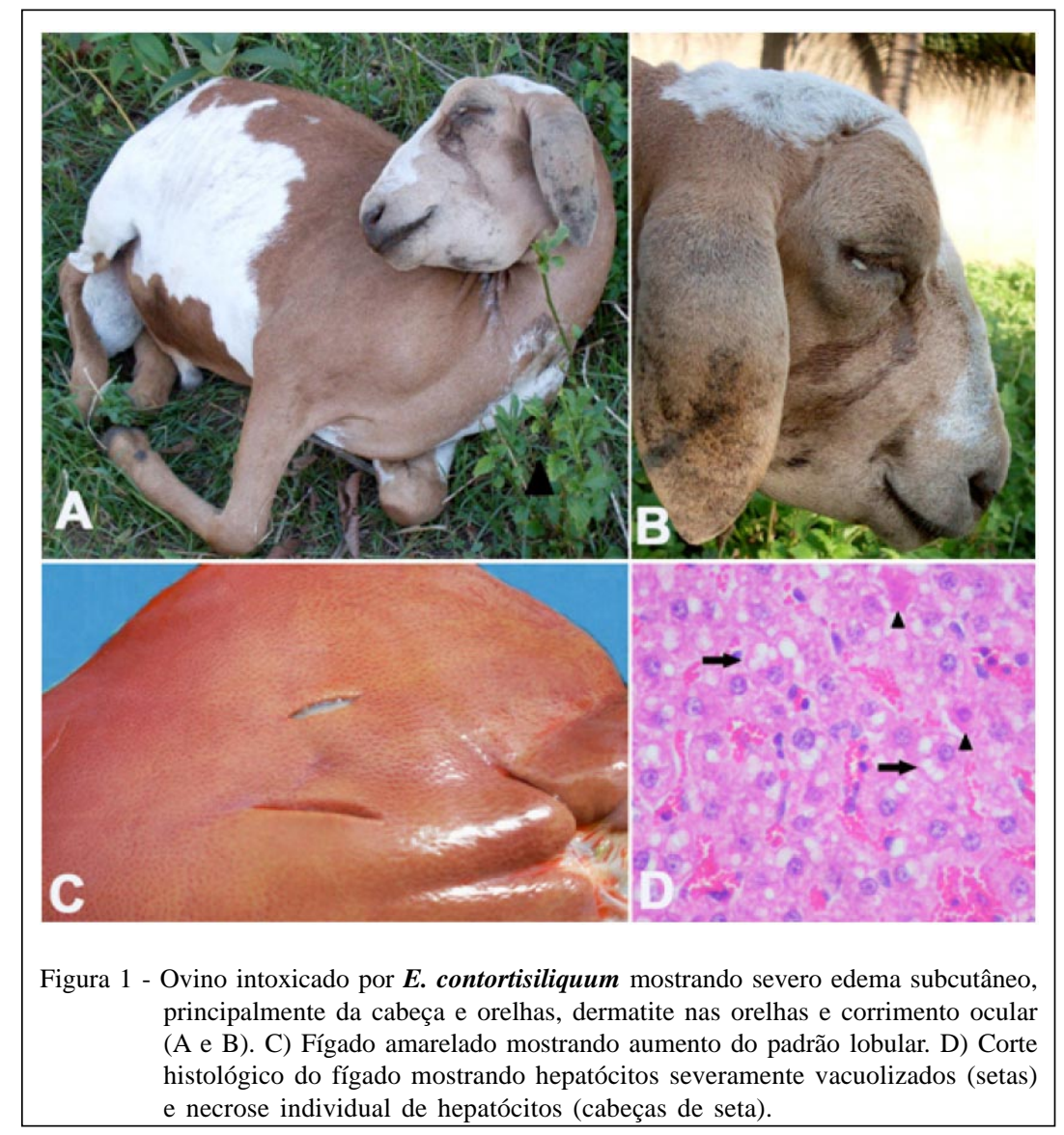

Ciência Rural, v.42, n.6, jun, 2012. 
únicos, enquanto outros apresentavam múltiplos vacúolos e citoplasma consideravelmente aumentado de volume (Figura 1D). Havia necrose individual aleatória de hepatócitos.

Malformações semelhantes às observadas na intoxicação por Mimosa tenuiflora foram relatadas em caprinos, ovinos e/ou bovinos por oito (38\%) dos entrevistados em fazendas onde ocorria $\boldsymbol{M}$. tenuiflora. Mascagnia rigida foi relatada por oito (38\%) dos entrevistados por causar morte súbita em bovinos, associada ao exercício. Um técnico agrícola relatou ter observado intoxicação em ovinos e bovinos. Brachiaria decumbens foi relatado por oito (38\%) dos entrevistados por causar fotossensibilização em bovinos e ovinos. Manihot spp. foi relatada por seis (28\%) dos entrevistados como causa de intoxicação com morte hiperaguda em ruminantes. Um médico veterinário relatou que diagnostica presuntivamente aproximadamente 10 surtos de intoxicação por ano, principalmente em caprinos. Um técnico agrícola relatou ter ocorrido intoxicação em um suíno que ingeriu a manipueira (líquido branco-amarelado subproduto resultante da compressão da massa de mandioca ralada obtida em grande quantidade nas casas de farinha). Outro médico veterinário relatou que na região muitos produtores fornecem a casca da raiz (subproduto das casas de farinha) para vacas em lactação sem o conhecimento do manejo e ocorrem frequentes casos de intoxicação por este subproduto. Anadenanthera colubrina var. cebil foi relatada como tóxica por três (14\%) dos entrevistados que observaram morte após sinais hiperagudos em bovinos que ingeriram esta planta. Ricinus communis foi relatada por três (14\%) dos entrevistados que afirmam ter observado sinais digestivos em bovinos intoxicados por esta planta. Dos 21 entrevistados, 16 (76\%) afirmaram existir a Thiloa glaucocarpa na região e dois (9\%) afirmaram ter visto casos de intoxicação por esta planta em bovinos.

Leucaena leucocephala foi relatada por um (4\%) entrevistado que afirmou ter observado um equino e 18 ovinos deslanados (45\% do rebanho) intoxicados. Dos 18 ovinos, 10 morreram e 8 se recuperaram. Os ovinos apresentaram alopecia e perda de peso. O equino apresentou perda dos pêlos da crina e da cauda. Os animais se intoxicaram por ter invadido a área cultivada com leucena (que servia como banco de proteína) e permaneceram por muito tempo nesta área alimentandose da planta. Sorghum halepense foi relatada por um (4\%) entrevistado que mencionou a ocorrência periódica de intoxicação em bovinos apresentando instabilidade, tremores musculares, timpanismo, decúbito lateral e morte em três até horas. Na propriedade, havia invasão de $\boldsymbol{S}$. halepense, principalmente em áreas mais baixas.
Plantas citadas por alguns entrevistados como tóxicas, mas sem comprovação científica anterior

Casearia commersoniana Camb. (café-brabo, café-bravo) foi relatada por dois (9\%) dos entrevistados como causa de morte em caprinos no município de Crato. Umprodutor relatou que, de um rebanhode aproximadamente 54 animais, morreram quatro caprinos em 2007, quatro caprinos em 2008 e três caprinos em 2009, em decorrência da intoxicação por esta planta, quando os caprinos se alimentavam dos frutos diretamente no arbusto. Afirmou também que anteriormente todos os anos morriam 4 a 5 animais com sinais clínicos de aumento de volume do abdômen, quedas e morte. A morte ocorria de forma hiperaguda, geralmente após exercícios ou quando os animais retornavam aos currais após pastejar em área severamente invadida pela planta. Ovinos não adoecem, porque não comem os frutos da planta. C. commersoniana. (Figura 2) é um arbusto que frutifica na região durante mês de outubro e é encontrado no alto da Chapada do Araripe. Uma amostra dessa planta foi arquivada no Herbário Caririense Dárdano deAndrade Lima, voucher número 4753.

Foram realizados experimentos com os frutos desta planta que foram administrados a cinco caprinos (Tabela 1). O caprino 3, que recebeu dose diária de $20 \mathrm{~g}$ $\mathrm{kg}^{-1}$ durante três dias, apresentou relutância em movimentar-se, discreto timpanismo, polaquiúria, vocalização, dispneia com postura ortopneíca, andar cambaleante e quedas, mostrando bradicardia e bradipnéia, opistótono e movimentos de pedalagem. Após alguns minutos em repouso, o animal levantou-se e apresentou taquicardia (140bpm) e taquipneia (40mpm), relutância em movimentar-se, vocalização frequente e posteriormente decúbito esterno abdominal. No dia seguinte (13 horas após o início dos sinais), o animal foi encontrado em decúbito esternal com vocalização frequente e apresentando opistótono, levantava-se e deitava-se em sinais de inquietude. Após uma hora, morreu. O caprino 4, que recebeu dose diária de $20 \mathrm{~g} \mathrm{~kg}^{-1}$ durante 4 dias, apresentou aumento da frequência cardíaca (112bpm), aumento da frequência respiratória (57mpm), posição com aumento da base de sustentação, dispneia com posição ortopneica, pulso jugular evidente, extensão do pescoço, timpanismo moderado, quedas, dificuldade para andar (membros espásticos, principalmente os posteriores), bruxismo e micção e defecação frequentes.

À necropsia, observou-se edema pulmonar e hidrotórax no caprino 3 e presença de grande quantidade de frutos da planta no interior do rúmen dos caprinos 3 e 4. Na histopatologia, foi observada, nos dois animais, vacuolização de hepatócitos com distribuição predominantemente centro-lobular a médio-zonal. No caprino 3, havia edema pulmonar, preferentemente intersticial e da pleura. 


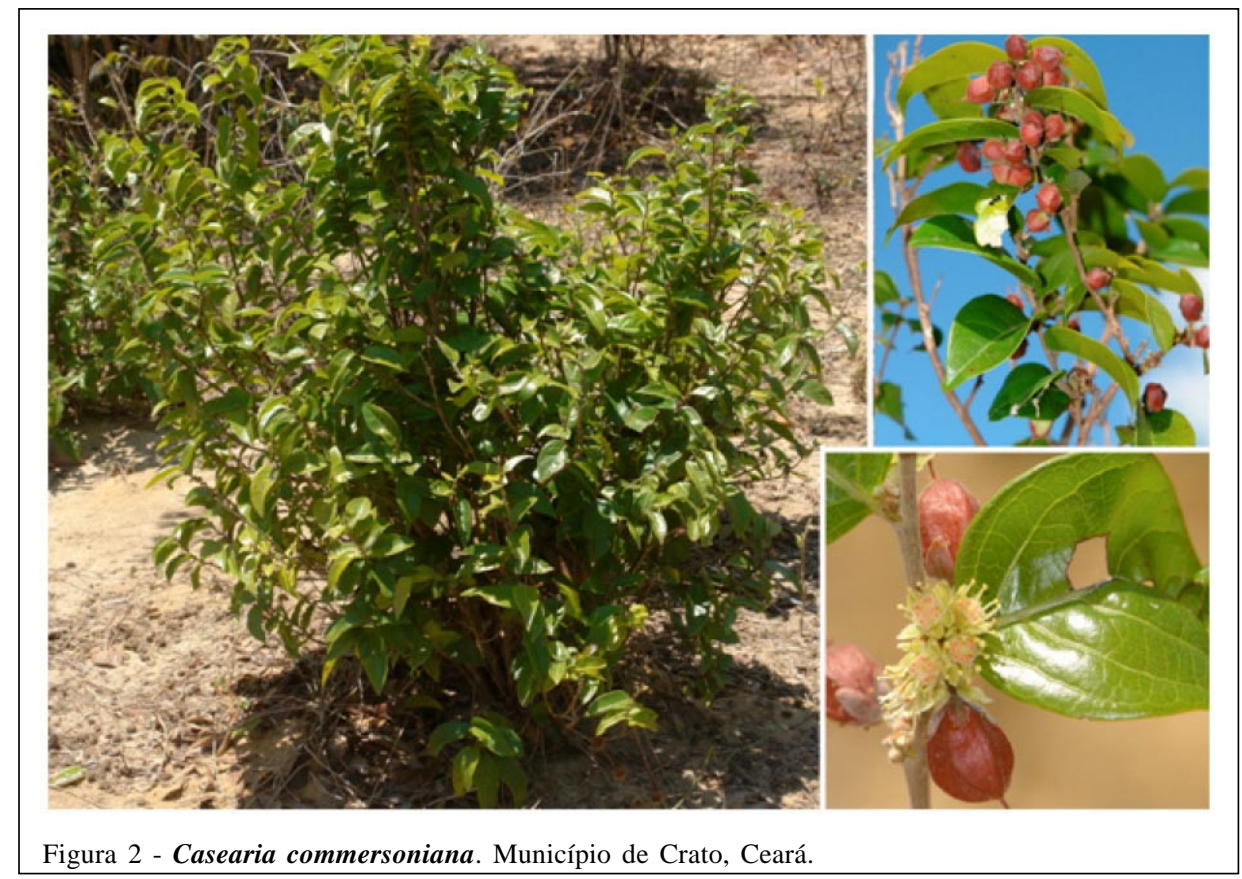

Mimosa malacocentra Mart. foi descrita por dois entrevistados (9\%) como tóxica para bovinos e caprinos causando diarreia por vários dias, levando o animal à morte. Folhas de $\boldsymbol{M}$. malacocentra foram administradas a um ovino durante 10 dias na dose diária de $10 \mathrm{~g} \mathrm{~kg}$ de peso vivo. O animal apresentou fezes pastosas durante o terceiro dia do experimento, mas no dia seguinte as fezes estavam normais. Não foram vistos outros sinais clínicos. Um entrevistado relatou que Marsypianthes chamaedrys Vahl. Kuntze seria responsável por provocar aborto em quatro caprinos com quatro meses de gestação nos meses de novembro a janeiro de 2006. Segundo o entrevistado, os fetos já estavam formados, mas, em uma cabra, os fetos nasceram sem pêlos, porém vivos, morrendo depois de alguns dias. Serjania lethalis foi relatada por dois entrevistados como tóxica para bovinos e caprinos causando diarreia. Folhas de $\boldsymbol{S}$. lethalis foram administradas a um ovino durante oito dias na dose diária de $10 \mathrm{~g} \mathrm{~kg}^{-1}$ peso vivo, sem que apresentasse sinais clínicos. Zizyphus joazeiro Mart foi relatado por um entrevistado por causar morte de caprinos após terem ingerido grande quantidade do fruto. Os animais ficam abatidos, com mucosa pálida e sangue claro. Frutos de juazeiro, na íntegra, recentemente colhidos, foram administrados ad libitum a dois caprinos, pesando 18 e $19 \mathrm{~kg}$, respectivamente, durante 30 dias. Simultaneamente, era administrada pastagem cortada formada principalmente por gramíneas. Os caprinos ingeriram, diariamente, entre 50 e $80 \mathrm{~g} \mathrm{~kg}^{-1}$ de peso corporal de frutos de juá e não apresentaram nenhum sinal clínico.
Magonia pubescens foi relatado por um entrevistado por causar intoxicação com morte súbita em bovinos. Folhas de M. pubescens foram administradas a um caprino durante cinco dias na dose diária de $15 \mathrm{~g} \mathrm{~kg}^{-1} \mathrm{pv}^{-1}$, sem que apresentasse sinais clínicos.

\section{DISCUSSÃO}

Os resultados obtidos mediante a aplicação do formulário 1 sugerem que I. asarifolia, mencionada por $38 \%$ e $19 \%$ dos entrevistados como tóxicas para bovinos e ovinos, respectivamente, e E. contotisiliquum mencionada como tóxica para bovinos (47,6\% dos entrevistados) e ovinos (4,7\%) são as plantas que mais frequentemente causam intoxicações na região, a qual têm uma população de 53.473 bovinos, 9.149 ovinos, 4.799 caprinos e 7.060 equídeos. Outras plantas tóxicas, de aparente menor importância, são $\boldsymbol{M}$. rigida (mencionada por 38\% do entrevistados), Manihot spp. (28\%), A. colubrina var. cebil (14\%), R. communis (14\%), T. glaucocarpa (9\%) e $\boldsymbol{S}$. halepense (4\%) para bovinos, B. decumbens para ovinos e bovinos (38\%), $\boldsymbol{M}$. tenuiflora para ovinos, caprinos e bovinos (38\%) e $\boldsymbol{L}$. leucocephala para ovinos e equinos (4\%).

Semelhante ao que ocorre em outras regiões do semiárido brasileiro, a intoxicação mais frequente é a intoxicação por I. asarifolia, que afeta principalmente ovinos jovens, mas também caprinos e bovinos, na época seca (SILVA et al., 2006; MELLO et al., 2010). No entanto, no Cariri Cearense, a espécie mais afetada foi a bovina, 
Tabela 1 - Experimento de toxicidade dos frutos de Casearia commersoniana administrado a caprinos.

\begin{tabular}{|c|c|c|c|c|c|c|c|}
\hline \multirow{2}{*}{ Caprino $\mathrm{n}^{\mathrm{o}}$} & \multirow{2}{*}{ Data } & \multirow{2}{*}{$\begin{array}{l}\text { Peso do animal } \\
\text { (kg) }\end{array}$} & \multirow{2}{*}{$\begin{array}{l}\text { Dose diária } \\
\quad\left(\mathrm{g} \mathrm{kg}^{-1}\right)\end{array}$} & \multirow{2}{*}{$\begin{array}{c}\text { Dias de } \\
\text { administração }\end{array}$} & \multirow{2}{*}{$\begin{array}{c}\text { Dose total } \\
\text { ingerida }\end{array}$} & \multicolumn{2}{|l|}{ Sinais clínicos } \\
\hline & & & & & & Início após administração & Duração \\
\hline 1 & 28/10/2009 & 7,4 & 10 & 4 & $296 g$ & Sem sinais & - \\
\hline 2 & 04/10/2010 & 9,2 & 10 & 10 & $920 \mathrm{~g}$ & Sem sinais & - \\
\hline 3 & 02/11/2010 & 12 & 20 & 3 & 720 & 49 horas & 19 horas \\
\hline 4 & $01 / 11 / 2009$ & 7,4 & 20 & 4 & $592 \mathrm{~g}$ & $4^{\underline{0}}$ dia & 6 horas \\
\hline 5 & 19/11/2009 & 7,5 & 20 & 10 & $1.500 \mathrm{~g}$ & Sem Sinais* & - \\
\hline
\end{tabular}

*Os frutos administrados a este animal, na sua maioria, não continham sementes, encontrando-se as cápsulas vazias.

devido provavelmente ao maior número de bovinos na região. Outra intoxicação importante no Cariri Cearense éa causada por frutos de $\boldsymbol{E}$. contortisiliquum em bovinos. A intoxicação por esta planta também ocorre em diversas regiões do semiárido, mas, aparentemente, com menor frequência da observada neste trabalho. Foi realizado, também, um diagnóstico de intoxicação por esta planta em um ovino, com fotossensibilização, que apresentava sementes no rúmen e lesões hepáticas. No nordeste, $\boldsymbol{E}$. contortisiliquum é descrito, também, como causa de sinais digestivos e abortos em caprinos (BENÍCIO et al., 2007).

Um produtor mencionou a ocorrência de um surto de intoxicação por $\mathbf{L}$. leucocephala em equinos e ovinos. Esta é uma leguminosa utilizada no semiárido brasileiro como fonte de proteína (GUIMARAES FILHO et al., 1995). No entanto, apresenta toxicidade quando é o principal constituinte da dieta. No Brasil, a intoxicação tem sido diagnosticada em ovinos (RIET-CORREA et al., 2004), caprinos (PEIXOTO et al., 2008) e equinos (PIMENTEL et al., 2009). No trabalho de PIMENTEL et al. (2009), equinos e bovinos eram alimentados com galhos de $\mathbf{L}$. leucocephala, sendo que os equinos foram afetados após 10 dias de consumo e os bovinos não. Para a utilização desta leguminosa como forrageira, o acesso aos piquetes com leucena deve ser limitado a uma hora diária de pastejo (GUIMARAES FILHO et al., 1995) e, se for administrada após o corte, a quantidade diária não deve superar 25\%-30\% da dieta. Resultados negativos em uma cabra que ingeriu $L$. leucocephala, como único alimento, por um período de 60 dias sugerem que, na caatinga, onde ocorrem diversas espécies de Mimosa, há animais resistentes à intoxicação, provavelmente por terem, no rúmen, bactérias que hidrolisam mimosina(RIET-CORREA et al., 2004).

Dentre as plantas anteriormente desconhecidas como tóxicas, foi constatada a toxicidade de $\boldsymbol{C}$. commersoniana para caprinos. A reprodução experimental da intoxicação em caprinos comprovou que os casos mencionados pelos produtores são realmente causados pela ingestão espontânea de frutos de $\boldsymbol{C}$. commersoniana. Em consequência, esta planta deve ser considerada como uma nova espécie brasileira tóxica. Os sinais clínicos observados, principalmente nervosos, mas também cardíacos, respiratórios e digestivos e a ausência de lesões macroscópicas e histológicas de significação não permitiram determinar qual o sistema afetado. A falha na reprodução da doença em um caprino que ingeriu, durante 10 dias, as cápsulas, a maioria sem sementes, na dose de $20 \mathrm{~g} \mathrm{~kg}^{-1}$ sugere que o princípio ativo desconhecido da planta está presente nas sementes. Novos experimentos com as sementes a as cápsulas sem sementes deverão ser realizados para comprovar esta hipótese.

Um produtor mencionou casos de intoxicação em animais ingerindo frutos de Zizyphus joazeiro. Em outras regiões do semiárido, incluindo o Cariri Paraibano, produtores relatam que ovinos e caprinos adoecem após ingerir frutos de juazeiro em forma continuada. Outros produtores mencionam que o consumo de juá leva os animais a uma verminose grave. Os experimentos nos quais foram administrados frutos de juá ad libitum, além de pasto cortado, demonstraram que os frutos não são tóxicos. No entanto, é provável que estes, assim como outras frutas, causem acidose ruminal quando ministrados como único alimento ou como alimento preferencial. Outra possibilidade é que, como na época de frutificação há grande produção de juá, os animais permanecem muito tempo em áreas pequenas nas proximidades das árvores para ingerir as frutas, o que pode resultar em uma alta infestação por parasitas gastrintestinais e os produtores associam os sinais clínicos com a ingestão de juá. Situação semelhante ocorre com outras frutas nativas do semiárido ou do cerrado como o cajá (Spondias luta), a mirindiba (Buchenavia tomentosa) (MELLO et al., 2010) e a cagaita (Eugenia dysenterica), que, mesmo sendo comestíveis, são responsabilizadas pelos produtores como causa de intoxicação em ruminantes.

\section{AGRADECIMENTOS}

Este trabalho foi financiado pelo Instituto Nacional de Ciência e Tecnologia (INT) Para o Controle das Intoxicações 
por Plantas, Processo Conselho Nacional de Desenvolvimento Científico e Tecnológico (CNPq) 573534/2008-0.

\section{COMITÊ DE ÉTICA E BIOSSEGURANÇA}

Declaração nos documentos suplementares. Declaramos, para os devidos fins, que assumimos toda e qualquer responsabilidade sobre os procedimentos que foram realizados no trabalho intitulado Plantas tóxicas para ruminantes e equídeos da microrregião do Cariri Cearense. Da mesma forma, colocamonos à disposição para quaisquer esclarecimentos que se façam necessários.

\section{REFERÊNCIAS}

ASSIS, T.S. et al. Intoxicações por plantas no Sertão Paraibano. Pesquisa Veterinária Brasileira, v.19, p.919-924, 2009. Disponível em: <http://www.pvb.com.br/pdf_artigos/31-122009_22-53Vet682.pdf>. Acesso em: 15 maio 2010. doi: 10.1590/S0100-736X2010000100003.

ASSIS, T.S. et al. Intoxicações por plantas diagnosticadas em ruminantes e equinos e estimativa das perdas econômicas na Paraíba. Pesquisa Veterinária Brasileira, v.30, n.1, p.1320, 2010. Disponível em: <http://www.pvb.com.br/pdf_artigos/ 30-01-2010_17-20Vet690.pdf $>$. Aceso em: 8 mar. 2010. doi: 10.1590/S0100-736X2009001100010.

BENÍCIO, T.M.A. et al. Intoxication by the pods of Enterolobium contortisiliquum in goats. In: PANTER K.E. et al. Poisonous plants: global research and solutions. Wallingford: CAB International, 2007. p.67-71.

GUIMARAES FILHO, C. et al. Sistema caatinga-buffelleucena para produção de bovinos no semi-árido. Petrolina, PE: EMBRAPA CPATSA, 1995. 39p. (Circular Técnica, 34).

IBGE, Cidades@. Rio de janeiro, 2011. Acesso em: 05 jun. 2011. Online. Disponível em: <http://www.ibge.gov.br/cidadesat/ topwindow.htm?1>.
MELLO, G.W.S. et al. Plantas tóxicas para ruminantes e eqüídeos no Norte Piauiense. Pesquisa Veterinária Brasileira v.30, n.1, p.1-9, 2010. Disponível em: <http://www.scielo.br/ s cielo.ph p ? c c i p t = sci_art text \& pid=S 0100 $736 \times 2010000100001 \& \operatorname{lng}=p t \& n r m=i s o \& t \operatorname{lng}=p t>$. Acesso em: 8 nov. 2010. doi: 0.1590/S0100-736X2010000100001.

PEIXOTO, P.V. et al. Intoxicação espontânea por Leucaena leucocaphala em uma cabra, no Rio de Janeiro, Brasil. Ciência Rural v.38, n.2, p.551-555, 2008. Disponível em: <http:// www.scielo.br/scielo.php?script=sci_arttext\&pid=S0103$84782008000200044 \& \operatorname{lng}=\mathrm{en} \& n r m=\mathrm{iso} \& \ln g=\mathrm{en}>$. Acesso em: 10 mar. 2010. doi: 10.1590/S0103-84782008000200044.

PIMENTEL, L.A. et al. Intoxicação espontânea por Leucaena leucocephala em equinos. In: ENCONTRO NACIONAL DE PATOLOGIA VETERINÁRIA, 14., 2009. Anais... Águas de Lindóia-SP: Associação Brasileira de Patologia, 2009. (CD Room).

RIET-CORREA, F.; MEDEIROS, R.M.T. Intoxicações por plantas em ruminantes no Brasil e no Uruguai: importância econômica, controle e riscos para a saúde pública. Pesquisa Veterinária Brasileira, v.21, n.1, p.38-42, 2001. Disponível em: <http:// www.scielo.br/scielo.php?script=sci_arttext\&pid=S0100$736 X 2001000100008 \& \operatorname{lng}=e n \& n r m=i s o \& t \operatorname{lng}=p t>$. Acesso em: 5 set. 2010. doi: 10.1590/S0100-736X2001000100008.

RIET-CORREA, F. et al. Intoxicação por Leucaena leucocephala em ovinos na Paraíba. Pesquisa Veterinária Brasileira, v.24, Supl, p.52, 2004.

SILVA, D.M. et al. Plantas tóxicas para ruminantes e eqüídeos no Seridó Ocidental e Oriental no Rio Grande do Norte. Pesquisa Veterinária Brasileira, v.26, n.4, p.223-236, 2006. Disponível em: <http://www.scielo.br/ s c i e lo.ph p ? s c ri p t = s c i_art text \& pid = S 0100 $736 \mathrm{X} 2006000400007 \& \operatorname{lng}=\mathrm{en} \& \mathrm{nrm}=\mathrm{iso} \& \mathrm{t} \operatorname{lng}=\mathrm{pt}>$. Acesso em: 5 set. 2010. doi: 10.1590/S0100-736X2006000400007. 